\title{
LOG AND HARMONICALLY LOG-CONVEX FUNCTIONS RELATED TO MATRIX NORMS
}

\author{
MOHAMMAD SABABHEH
}

Abstract. In this article, we introduce the concept of harmonically log-convex functions, which seems to be strongly connected to unitarily invariant norms. Then, we prove Hermite-Hadamard inequalities for these functions. As an application, we present many inequalities for the trace operator and unitarily invariant norms.

Mathematics subject classification (2010): 47A30, 47B15, 15A15.

Keywords and phrases: Unitarily invariant norm inequalities, Heinz means, convex functions, logconvex functions.

\section{REFERENCES}

[1] R. Bhatia, Matrix analysis, Springer-Verlag, New York, 1997.

[2] J. Bourin, Some inequalities for norms on matrices and operators, Linear Algebra Appl. 292 (1999) 139-154.

[3] E. CARLEN, Trace Inequalities and Quantum Entropy: An Introductory Course, Contemp. Math. 529 (2009).

[4] C. Conde, Young type inequalities for positive operators, Ann. Funct. Anal. 4 (2013) no. 2, 144-152.

[5] S. S. Dragomir, B. Mond, Integral inequalities of Hadamard type for log-convex functions, Demonstratio Mathematica, 31 (1998) no. 2, 354-364.

[6] Y. FEnG, Refinements of the Heinz inequalities, Journal of Inequalities and Applications, 2012:18. Doi:10.1186/1029-242X-2012-18.

[7] F. Hiai, H. Kosaki, Comparison of various means for operators, J. Funct. Anal. 163 (1999), 300323.

[8] F. HIAI, X. ZHAN, Inequalities involving unitarily invariant norms and operator monotone functions, Linear Algebra Appl. 341 (2002), 151-169.

[9] I. IsCAN, S. WU, Hermite-Hadamard type inequalities for harmonically convex functions via fractional integrals, Applied Mathematics and Computation, 238 (2014), 237-244. doi:10.1016/j.amc.2014.04.020.

[10] R. Kaur, M. Moslehian, M. Singh, C. Conde, Further refinements of the Heinz inequality, Linear Algbera Appl. 447 (2013), 26-37. http://dx.doi.org/10.1016/j.laa. 2013.01.012.

[11] F. Kittaneh, Norm inequalities for fractional powers of positive operators, Lett. Math. Phys. 27 (1993), 279-285.

[12] F. Kittaneh, On the convexity of the Heinz mean, Integr. Equ. Oper. Theory, 68 (2010), 519-527.

[13] M. A. Noor, K. I. Noor And M. U. Awan, Some characterization of harmonically log-convex functions, Proc. Jangjeon Math. Soc. 17, 1 (2014), 51-61.

[14] M. S ABABheH, A. Yousf, R. KhaliL, Interpolated Young and Heinz inequalities, Linear and Multilinear Algebra, 63 (2015) no. 11, 2232-2244. doi:10.1080/03081087.2014.1000816.

[15] M. SaвABHeH, Interpolated inequalities for unitarily invariant norms, Linear Algebra Appl., 475 (2015), 240-250. doi:10.1016/j.laa.2015.02.026.

[16] M. SABABHEH, Integral Inequalities of the Heinz Means as Convex Functions, J. Math. Inequal., 10, 2 (2016), 313-325. 